\title{
A CONSTRUÇÃO VISUAL DE UMA COMUNIDADE IMAGINADA PARANAENSE NAS COMEMORAÇÕES AO CENTENÁRIO DO PARANÁ (1953)
}

\section{THE VISUAL CONSTRUCTION OF A PARANA'S IDENTITY IN CELEBRATIONS TO CENTENARY OF PARANÁ (1903-1953)}

\author{
Alvaro Luiz Nunes ${ }^{1}$
}

Resumo: Este estudo tem como objetivo central investigar a participação das imagens fotográficas na construção da comunidade imaginada paranaense em duas revistas patrocinadas pelo governo e publicadas por ocasião do Centenário de Emancipação Política do Paraná, ocorrido em dezenove de dezembro de 1953, para rememorar o evento histórico de sua emancipação política. Através da análise do assunto das imagens, e depois de feita a seleção de um conjunto iconográfico de teor identitário, que neste estudo entendemos serem imagens que foram instrumentalizadas para representarem uma especificidade para o Paraná, tentaremos elencar alguns aspectos associados à uma nova identidade no âmbito da comunidade imaginada paranaense.

Palavras-chave: Paraná; identidade; centenário; emancipação; política.

Abstract: The objective of this study is to investigate the role of images in the construction of Parana's identity in journals published by the government during the Cinquantenaire and Centennial of Emancipation Policy of Parana, occurred in 1953, to remember of the historical event of their political emancipation. After analyzing the images, we will select a set of images of identity content, which in this study we believe they are

\footnotetext{
${ }^{1}$ Estudante do curso de História Memória e Imagem. Orientado pela professora Doutora Rosane Kaminski.
} 
images that have been manipulated to represent a specific character to Paraná, we will try to list some aspects associated with Paraná identity. Keywords: Paraná; identity; centenary; emancipation; policy.

\section{Introdução}

Quando, em dezenove de dezembro de 1853, a quinta comarca de São Paulo consegue, finalmente, sua emancipação política e se torna a província do Paraná, iniciam-se os esforços das elites locais para a criação de uma identidade paranaense (Bahls, 2007); isto é, começa a busca incessante por elementos que diferenciassem o Paraná das demais províncias do Brasil, sobretudo de São Paulo, da qual havia se desmembrado, e que pudessem estreitar os laços entre os habitantes da nova província, fazendo com que estes se identificassem com algo que os tornasse paranaenses.

A data comemorativa do Centenário do Paraná foi escolhida para este estudo por entendermos que este tipo de festa cívica se configura em um meio importante pelo qual as elites intencionam atingir seus objetivos, e a construção e manutenção da identidade, nesta perspectiva, se torna estratégica.

De acordo com Silva (2002), narrativas coletivas ganham força através de comemorações públicas que possuem a função de cristalizar memórias coletivas e individuais por meio da potencialização da lembrança, no processo de rememoração de eventos marcantes da história coletiva.

Ao trabalharmos com a comemoração de uma data cívica organizada pelas elites a fim de reivindicar e/ou reafirmar uma identidade para 
o Paraná, tendo como uma de suas estratégias a intervenção no passado para justificar o presente, nos parece adequado abordar a Memória enquanto mecanismo ideologizado e concebido para encobrir relações de poder (Ricoeur, 2007).

Em sua tese sobre a busca identitária paranaense, a historiadora Aparecida Vaz da Silva Bahls (2007) argumentou que a identidade que o governo Bento Munhoz da Rocha Neto buscou construir naquela conjuntura marcou um momento de inflexão nas buscas pela identidade do Paraná. Diferentemente das narrativas identitárias anteriores, pautadas em aspectos relacionados ao passado e elementos tradicionais da região, Bahls afirma que Munhoz da Rocha apostou em uma identidade em consonância com os valores modernos que permeavam o período, e os monumentos construídos para o Centenário seriam marcos memorativos voltados para o devir.

Geraldo Leão Veiga de Camargo (2007), ao trabalhar em torno das soluções intelectuais e visuais que escritores e artistas plásticos, a serviço das elites, elaboraram para representar a identidade paranaense fato que se tornou urgente após a emancipação da província em 1853 -, identificou a "Elaboração de uma idéia moderna de nação, no caso uma região, com a construção ou a manutenção de um projeto de poder, social e político tradicional (ibedem,p.12).

Nosso objetivo nesta pesquisa é investigar a participação das imagens como um dos mecanismos utilizados pelo governo para a construção da "nova identidade" no âmbito da comunidade imaginada paranaense. Para tanto, nossas fontes foram duas revistas patrocinadas pelo 
governo e publicadas durante os festejos, a saber, a revista intitulada $1^{\circ}$ Centenário da Emancipação Política do Paraná: 1853 - 1953 e o Álbum do Centenário.

\section{Imaginar uma comunidade e forjar a nação}

A fixação de datas para a comemoração de eventos históricos possui seu apogeu no século XIX, no contexto do nascimento das nações. Benedict Anderson (2008) argumenta que, com o processo de fragmentação, pluralização e territorialização das comunidades universalmente imaginadas pelas religiões, devido, entre outros fatores, à queda do latim e de línguas antigas que integravam comunidades sagradas e, sobretudo, com a ascensão do iluminismo no século XVIII, tornou-se necessário a construção de um novo sentimento de continuidade e pertencimento, e este vazio passou a ser preenchido com o nascimento da comunidade imaginada da nação, que estava baseada nos tradicionais sistemas culturais precedentes, inclusive naqueles em que o próprio nacionalismo veio combater (ibedem, p. 39).

De acordo com o autor, outras formas de imaginação preponderante para as construções nacionais, que propiciaram um senso de paralelismo (coincidência temporal) entre pessoas que nunca haviam se visto (ibedem, p. 258), foram o romance e o jornal, disseminados primeiramente na Europa do século XVIII (ibedem, p. 55). Essas formas de imaginação, por sua vez, só puderam ser disseminadas graças ao capitalismo editorial, haja vista que as línguas impressas e os "companheiros de leituras" foram o alicerce das comunidades imaginadas (ibedem, p.79). 
Assim, Andersen argumenta que "a ideia de um organismo atravessando cronologicamente um tempo vazio e homogêneo é uma analogia exata da ideia de nação, que também é concebida como uma comunidade sólida percorrendo constantemente a história" (ibedem, p. 56).

De acordo com o autor (ibedem, p. 264), as consciências nacionais foram responsáveis pela independência das Treze Colônias da América, pela Revolução Francesa e posteriormente, já na Segunda Geração do Nacionalismo, no século XIX, pelas independências das demais colônias americanas (ibedem, p. 266). Esses movimentos emancipatórios trouxeram a nação como novidade e representaram o momento supremo da ruptura com o passado, mas que não pôde permanecer assim por muito tempo (ibedem, p. 264), já que para se constituírem de maneira unificada, esses novos aglomerados políticos necessitavam de um passado.

Assim, iniciou-se o processo de transição do Novo para o Velho Tempo, em direção às glórias do passado (ibedem, p. 265), fazendo com que "a nacionalidade" passasse "a ser pensada em termos de continuidade (ibedem, p.267). A solução, então, tanto para o Velho quanto para o Novo Mundo, seria a História Oficial (ibedem, p. 269), e nesses esforços são criadas, no século XIX, as cátedras de História, cabendo aos historiadores a função de criar as imagens nacionais (ibedem). Não obstante, "os principais estados europeus oitocentistas eram enormes entidades políticas poliglotas (ibedem, p. 267) e, como a língua fora desde tempos remotos um elemento importante para se imaginar uma comuni- 
dade, as elites passaram a se preocupar com a questão das línguas nacionais.

Neste processo, as línguas aborígenes não seriam suficientes como forjadoras da nação, haja vista que as elites nacionais tinham vínculos imaginários com suas metrópoles e, apagar esses vínculos, seria apagar a memória da independência (ibedem, p. 268). Os nacionalistas da Segunda Geração passam, então, a falar pelos mortos (ibedem, p. 271), em construções imaginárias de um passado harmônico e fraterno, selecionando o que deve ser lembrado e esquecido (ibedem, p. 277).

Assim, o autor assinala que:

$\mathrm{O}$ que ocorre com as pessoas modernas ocorre também com as nações. A consciência de estarem inseridas no tempo secular e serial, com todas as suas implicações de continuidade e, todavia, de "esquecer" a vivência dessa continuidade - fruto das rupturas do final do século XVIII -, gera a necessidade de uma narrativa de identidade (ibedem, p. 279).

Este é o contexto no qual entra em cena o esforço dos governos para a criação de uma identidade nacional.

\section{A busca identitária como missão}

No Brasil, é também no século XIX que as elites buscam construir uma identidade nacional, urgente após a independência do país. Durante o processo de consolidação do Estado Nacional e do pensar a História de maneira sistematizada, é criado, em 1838, o Instituto Histórico e Geográfico Brasileiro (IHGB). Tal instituição, seguindo o modelo posi- 
tivista e ilustrado de História, tinha como objetivo forjar uma história nacional (Guimarães, 1988).

Por sugestão de Manuel de Araújo Porto Alegre, o IHGB passou a patrocinar artistas plásticos para que estes construíssem visualmente a identidade nacional (Camargo, 2007). O uso de imagens como instrumento para a construção identitária nacional remonta a este período. Os artistas visuais foram, desde o início das construções identitárias, importantes para que fossem criadas as imagens de identificação, tanto nacionais quanto regionais. $\mathrm{O}$ fato da maioria desses artistas serem filhos de imigrantes pobres, fez com que estivessem na maioria das vezes dependentes das elites para poderem estudar e adquirir trabalho. Geraldo Leão Veiga de Camargo (2007) argumenta que com frequência os artistas paranaenses eram contratados para reproduzir o discurso literário das elites através das artes plásticas. Este breve esboço serve para os mostrar que as imagens são importantes meios pelos quais as elites transmitem suas mensagens. Interessa-nos neste trabalho investigar a participação das imagens no discurso identitário promovido pelo governo e elites intelectuais em duas datas cívicas que rememoravam a Emancipação Política do Paraná.

As discussões sobre identidade se intensificaram no país a partir de 1870 , sob efeito de teorias racialistas de redenção das "raças inferiores", propagadas pela Escola de Direito de Recife e que culminariam, já no inicio do século XX, nas lutas regionais pela construção de identidades (Camargo, 2007). No Paraná, em 1880, trinta anos após a emancipação da província, a busca por valores identitários ganhou forma com a 
fundação do Clube Curitibano; sua revista foi um importante meio pelo qual os intelectuais luso-brasileiros propagaram suas ideias sobre a identidade cultural e social da mais nova província (Camargo, 2007).

A Belle Époque curitibana despontava no esteio da indústria do mate, principal atividade econômica daquele período no estado e que permitiu uma relativa modernização da cidade e um progresso econômico e cultural, ainda que este avanço estivesse limitado à Curitiba e seu entorno e beneficiado apenas a burguesia local (Borges; Fressato, 2008).

Em 1900 foi criado o Instituto Histórico e Geográfico Paranaense e, mais tarde, em 1927, a revista Ilustração Paranaense tem o seu primeiro volume publicado, sendo um importante instrumento para a divulgação das ideias paranistas, ${ }^{2}$ um movimento artístico, intelectual e político formado pela nata da intelectualidade paranaense que teve como objetivo construir uma identidade para o Paraná, baseada em elementos de sua paisagem natural, tendo o pinheiro sido eleito o símbolo máximo para representar a especificidade do Paraná. (Bahls,2007,p.21). Estes esforços promovidos pelas elites paranaenses no alvorecer do século XX e que visavam a construção de uma identidade específica para o Paraná, se apresentam como a consolidação de tentativas de construção identitária que remontam a criação da província (Bahls, 2007).

\footnotetext{
${ }^{2}$ Sobre o movimento paranista, ver: PEREIRA, Luís Fernando Lopes. Paranismo: O Paraná Inventado. Cultura e imaginário no Paraná da I República. Curitiba: Aos Quatro Ventos, 1998.
} 


\section{Memória e identidade: uma ferida aberta}

A partir dos estudos de Emile Durkheim sobre o Fato Social, o sociólogo francês Maurice Halbwachs se dedicou a analisar os fenômenos sociais da memória, identificados como memória coletiva (Bosi, 1987). Assim, de acordo com Ecléa Bosi (ibedem, p. 18), "Halbwachs amarra a memória da pessoa à memória do grupo; e esta última à esfera maior da tradição, que é a memória coletiva de cada sociedade”.

História e Memória não podem ser tomadas como sinônimo, haja vista que, ao contrário da segunda, a primeira tem como premissa a descontinuidade, o distanciamento, a crítica, a reflexão, além de ter a função de "investigar os elementos que foram sublimados ou mesmo ignorados pela memória" (Motta, 2012: p. 25).

A memória, por ser ela mesma uma história oficial não criticada e facilmente manipulada, é exercida de maneira a suscitar o sentimento de pertencimento em uma determinada comunidade, construindo uma narrativa identitária capaz de fortalecer e criar grupos, "muitas vezes em detrimento de outrem" (ibedem).

Lúcia Lippi Oliveira (1989) argumenta que as festas cívicas possuem um caráter pedagógico e unificador e, desta maneira, as diferenças existentes entre os grupos culturais tendem a ser reduzidas para que seja celebrado aquilo que, por convenção, foi decidido ser a memória oficial. As comemorações, enquanto lugares imateriais de memória ${ }^{3}$, "visam

\footnotetext{
3 O historiador Pierre Nora (1993) classificou as datas cívicas como "lugares imateriais de memória", argumentando que comemorações possuem valores simbólicos que são transmitidos em seus rituais; neles estaria arraigada uma "vontade de memória".
} 
consagrar a existência de uma unidade política nem sempre tranqüila" e possuem "um claro conteúdo pedagógico, ao imprimirem, ou buscarem imprimir, uma continuidade temporal com o passado [...] a partir dos valores do presente" (Motta, 2012: p.27).

\section{A fotografia como elemento para imaginar o paraná}

O aumento demográfico no Paraná, sobretudo nas regiões oeste e norte, propiciadas pela fertilidade da "terra roxa", tinha como principal causa a expansão da cafeicultura, motor da economia paranaense na década de 1950 e que em poucos anos asseguraria ao Paraná o título de maior produtor de café do Brasil (Paludo; Barros, 1995). O sentimento ufanista que levou as autoridades locais a conceber o Paraná como o mais próspero estado da federação e Curitiba como a cidade do futuro, ecoariam nas Comemorações do Centenário de Emancipação Política, em 1953.

Durante sua administração, o governador do Centenário, Bento Munhoz da Rocha Netto, concentrou seus esforços na construção de uma nova imagem do poder, e o símbolo deste estaria expresso na monumental arquitetura moderna (Bahls, 2007, p.163). Muitos dos intelectuais da época classificaram esta administração como produtora de idéias, o que teria conferido "ao Paraná sua primeira identidade [...] inserindo-o no contexto nacional" (ibedem). Dentre as obras monumentais construídas para serem inauguradas nos festejos do Centenário, destacam-se os monumentos instalados na Praça 19 de dezembro, o Teatro Guaíra, a nova sede da Biblioteca Pública do Paraná e o Centro Cívico, 
este último construído para afirmar Curitiba como capital de todos os paranaenses e, assim, unificar o Estado. (ibedem, p. 172).

De acordo com o historiador Ruy Christovam Wachowicz (2010), a formação histórica do Paraná passou por três estágios de colonização que se configuraram em três áreas histórico-culturais divididas. $\mathrm{O}$ chamado Paraná tradicional, cuja formação remonta a meados do século XVII e viria a se consolidar com a emancipação política da província, estaria relacionado à Curitiba, Ponta Grossa, Castro, Palmeira, Lapa, Litoral e vinculado às elites provinciais. O Paraná do Norte, colonizado inicialmente no século XIX e inteiramente ocupado nas décadas de 1950 e 1960, estaria, por sua vez, associado a paulistas, mineiros e imigrantes que se fixaram no local principalmente entre as décadas de 1940 e 1950. Já o Paraná do Oeste/Sudeste, começou a se formar na década de 1950, com a chegada de colonizadores catarinenses e gaúchos (Wachowicz, 2010: p. 327). Diante dessa fragmentação tripartite, que afastava do Paraná Tradicional os habitantes do Norte e os aproximava de São Paulo e Minas, bem como fazia os colonos do Oeste/ Sudeste a se identificarem mais com os catarinenses e gaúchos. Munhoz da Rocha e as elites políticas e intelectuais do Paraná decidiram pela construção de grandes marcos memorativos que afirmassem Curitiba como a capital de todos os Paranaenses (Bahls, 2007).

Neste processo, as revistas ilustradas que iremos analisar atuam na construção do senso de paralelismo (Anderson, 2008), pois paranaenses de outras cidades, sem nunca terem vindo para o Centro Cívico, poderiam aceitar Curitiba como sua capital. As imagens fotográficas dos 
monumentos atuariam na "partilha de uma memória objetivada a serviço de uma narrativa" (Meneses, 2012, p.258). A fotografia, uma imagem técnica, seria naturalizada, o que encobriria os conteúdos específicos do suporte e a imagem participaria do processo de rememoração (ibedem).

Aparecida Vaz da Silva Bahls (2007: p. 193) argumenta que a Memória que se desejou perenizar por meio dos monumentos arquitetônicos construídos durante a gestão Munhoz da Rocha estava pautada na ideia de progresso e modernidade, os quais eram possíveis, de acordo com o discurso do governo, graças ao trabalho morigerado do imigrante europeu. Charles Monteiro (2007) afirma que a partir da década de 1950 a arquitetura brasileira é repensada e começam a se levantar nas grandes cidades do país prédios de estilo modernista, um movimento que perseguiu o objetivo de transformar o "velho" no "novo", a fim de erguer cidades modernas, belas e funcionais, seguindo tendências internacionais na arquitetura.

Em 1951, o governo criou a Comissão Especial de Obras do Centenário, uma autarquia liderada pelo engenheiro Elato Silva, que tinha como função gerenciar as obras arquitetônicas que seriam construídas para serem inauguradas durante os festejos. O projeto mais ambicioso dessa comissão era a criação do primeiro Centro Cívico do país; um logradouro de 120.000 metros quadrados concebido para abrigar as sedes dos três poderes estaduais e suas secretarias (Rebelo, 2008).

O projeto de criação de um centro administrativo com vistas a garantir agilidade administrativa entre os órgãos estaduais estava previsto em um Plano de Urbanização de Curitiba da década de 1940, elaborado 
pelo urbanista francês Alfred Agache e que ficou popularmente conhecido como o Plano Agache (Bahls, 2007: p.164).

Para colocar em prática o projeto de Paraná moderno, o governo Munhoz da Rocha lutou em várias frentes, inclusive artísticas, contratando artistas e técnicos para a elaboração de um conjunto imagético que seria instrumentalizado para este intento. Afirmamos, junto com Ulpiano Bezerra de Meneses (2012: p 258), que a imagem possui força evocativa e caráter sensorial e afetivo. Estas atribuições favorecem seu uso social e permitem que elas sejam instrumentalizadas como discurso de poder. Monumentos públicos e memoriais, assim como imagens bidimensionais, têm o poder de partilhar a memória oficial. Nesse sentido, entendemos que as imagens e os monumentos fazem parte da dinâmica social.

Decidido a propagar uma imagem idealizada de seus feitos e sua administração, o governo Munhoz da Rocha investiu pesado em propaganda, num período em que a promoção pessoal de governantes ainda era permitida (Rebelo, 2005: p.221). A principal estratégia para divulgação do Paraná Moderno para sua população, e também ao resto do Brasil, foi a criação, nos Estados do Rio de Janeiro e São Paulo, da Câmara de Expansão Econômica e propaganda do Estado (ibedem). Expansão econômica só havia no título, haja vista que a função deste órgão era gastar com propaganda em jornais e revistas de todo o Brasil.Homero Braga, diretor do órgão, foi apelidado de Goebbels Paranaense pela oposição (ibedem). 
Esses investimentos em propaganda propiciaram a produção de duas importantes revistas ilustradas, todas publicadas em 1953, por ocasião do Centenário. A revista intitulada $1^{\circ}$ Centenário da Emancipação Política do Paraná: 1853 - 1953, dedicada a divulgar os atos administrativos do governo, trazia um corpo imagético composto por dezenas de fotografias. Já o Álbum do Centenário, como o nome indica, possuía somente imagens, acompanhada de legendas em tom poético. Essas revistas foram pagas pelo governo do Estado para apresentar aos paranaenses e ao Brasil, o "espetáculo de prosperidade" vivenciado no Paraná e, em nosso entendimento, o conjunto iconográfico que elas trouxeram foi instrumentalizado na construção da comunidade imaginada paranaense.

Nos circuitos sociais da fotografia, essas imagens são classificadas como fotografias públicas institucionalizadas, associadas "ao Estado e ao Capital, produzida pelas Agências do Estado para dar visibilidade às ações estatais em compasso com as estratégias de persuasão e publicação do poder político" (Lopes; Mauad, 2012: p.274).

Na década de 1950 houve um significativo aumento do uso de fotografia em impressos publicados no Brasil, sobretudo em razão da ampliação do espaço dedicado ao mercado publicitário e aumento do número de leitores, fato que ocasionou grandes avanços nas técnicas de editoração e diagramação (Monteiro, 2007).

No compasso dessas inovações, se destacavam meios de comunicação de massa como a revista O Cruzeiro, a Revista do Globo, Manchete, além da própria Ilustração Brasileira. Esses periódicos apresenta- 
vam narrativas modernas como as fotorreportagens; matérias que uniam estruturas narrativas distintas e independentes - texto e imagem - como técnica de abordagem (ibedem).

Desde sua existência como imagem técnica e fenômeno moderno, a fotografia tem sido importante no jogo social. No século XIX, por meio dos famosos autorretratos, a imagem técnica construiu a identidade da burguesia, ao mesmo tempo em que registrava o "outro" e construía alteridades sociais e culturais (Lopes; Mauad, 2012: p.271). Assim, “a fotografia serviria à estetização do mundo sendo um meio de alienação por meio do uso da magia da técnica naturalizada" (ibedem, p.266).

No que tange aos métodos e unidades normativas, o campo visual apresenta-se aberto (ibedem, p. 260), portanto, neste estudo escolhemos trabalhar as imagens enquanto "conjunto documental coletado em torno de um tema (ibedem).

As imagens dessas três publicações que selecionamos por concluirmos que possuem valores identitários, uma vez que em nosso entendimento intencionam forjar uma especificidade para o Paraná, diferenciando-o de outros Estados, são paisagens naturais e urbanas de enaltecimento ao meio. O discurso que exaltava as "maravilhas naturais" é, a partir de então, aplicado também à paisagem urbana e suas "maravilhas arquitetônicas". O progresso promovido pelo estado desenvolvimentista e o trabalho morigerado do imigrante, agora finalmente incorporado à 
tradição paranaense e homenageado por sua contribuição ${ }^{4}$, parece ter sido a aposta paranaense como elemento identitário.

Os três impressos publicados por ocasião das comemorações do Centenário de Emancipação política do Paraná apresentam imagens da paisagem natural paranaense, tendo o pinheiro aparecido diversas vezes, bem como o Salto das Sete Quedas, Vila Velha e Serra do Mar, os quais demonstram que os preceitos paranistas de identidade acompanharam Munhoz da Rocha até a década de 1950. Não obstante, percebe-se que as imagens de paisagens naturais dividem importância com imagens urbanas estetizadas que procuram expressar a verticalização de Curitiba através de ângulos estratégicos que apresentam a monumentalidade das construções arquitetônicas.

\footnotetext{
${ }^{4}$ Um discurso nacionalista construído na segunda metade do século XIX e que avançou até boa parte da primeira metade do século XX colocou os imigrantes estrangeiros como ameaça à cultura luso-brasileira.
} 


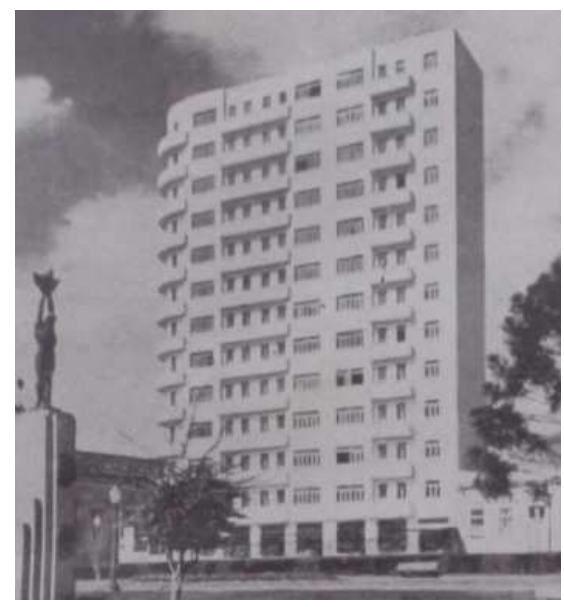

Figura 3: Arranha Céu Curitibano. A especificidade paranaense na arquitetura moderna. In $1^{\circ}$ Centenário da Emancipação Política do Paraná: 1853 - 1953. [S.1.]: Câmara de Expansão Econômica do Paraná, [1953].p. 131.

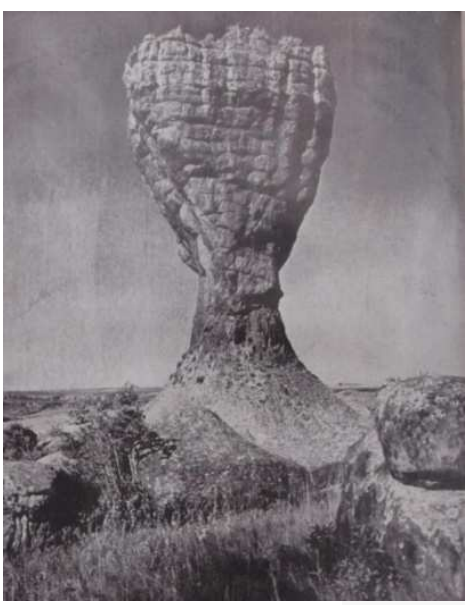

Figura 4: Vila Velha. A paisagem natural paranaense está presente como elemento identitário nas publicações analisadas referentes ao centenário, mas agora divide importância com a paisagem das cidades. In $1^{\circ}$ Centenário da Emancipação Política do Paraná: 1853 - 1953. [S.1.]: Câmara de Expansão Econômica do Paraná, [1953]. p 120.

Uma das estratégias usadas pelo governo para forjar uma identidade exclusiva paranaense, fundamentada na paisagem natural e arquitetônica, era explicitada em mensagens que tinham como objetivo intensificar o discurso estereotipado sobre a seca do nordeste e o povo nordestino (Motta, 2014), como podemos ver num dos discursos de Munhoz da Rocha na revista $1^{a}$ Centenário de Emancipação Política do Paraná: 1853 -1953, em que o governador se refere aos migrantes nordestinos desta maneira: "batidos pela clemência das secas, procuram o Paraná em 
ondas sucessivas "(Rocha Neto, 1953). Em uma das fotografias publicadas pelo governo em comemoração ao Centenário, um comerciante nordestino aparece ao lado de um edifício (FIGURA 06); a intenção da fotografia é sugerir o deslumbre do migrante diante das "maravilhas arquitetônicas do Paraná Moderno".

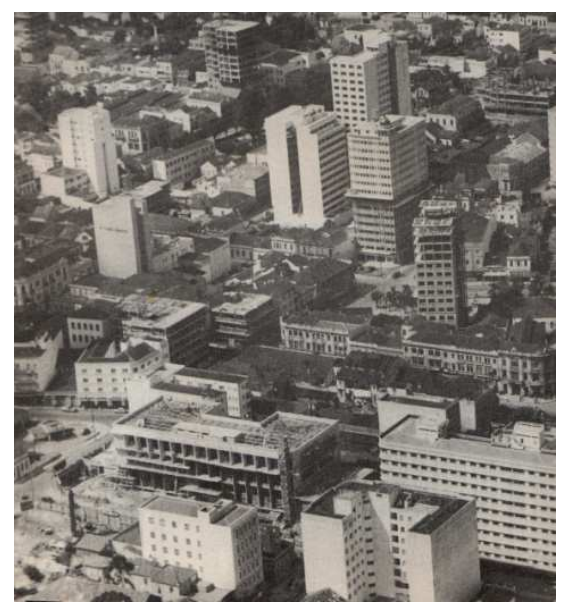

Figura 05: Erguem-se novos e altos edifícios. Fotografia aérea de Curitiba. In Álbum do Centenário [1953]

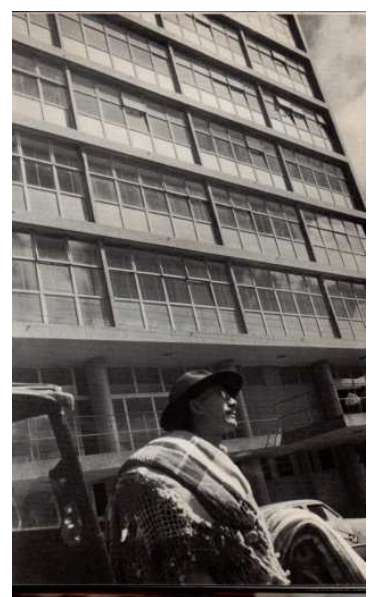

Figura 06: Nordestino em Londrina "admira a Canaã brasileira". In Álbum do Centenário [1953]

Exaustivamente presente na publicação intitulada $1^{\circ}$ Centenário da Emancipação Política do Paraná: 1853 - 1953, as imagens do projeto do Centro Cívico eram freneticamente exaltadas pelo governo como símbolo do progresso do Estado no ano do Centenário. Devido às geadas de julho de 1953, que devastaram boa parte das plantações de café, e a consequente crise econômica que culminou em medidas de austerida- 
Cadernos de Clio, Curitiba, v. 6, nº. 2, 2015

de, as obras do Centro Cívico não ficaram prontas para serem inauguradas nas festas do Centenário. Não obstante, como dito acima, fotografias do projeto do conjunto arquitetônico foram divulgadas energicamente.

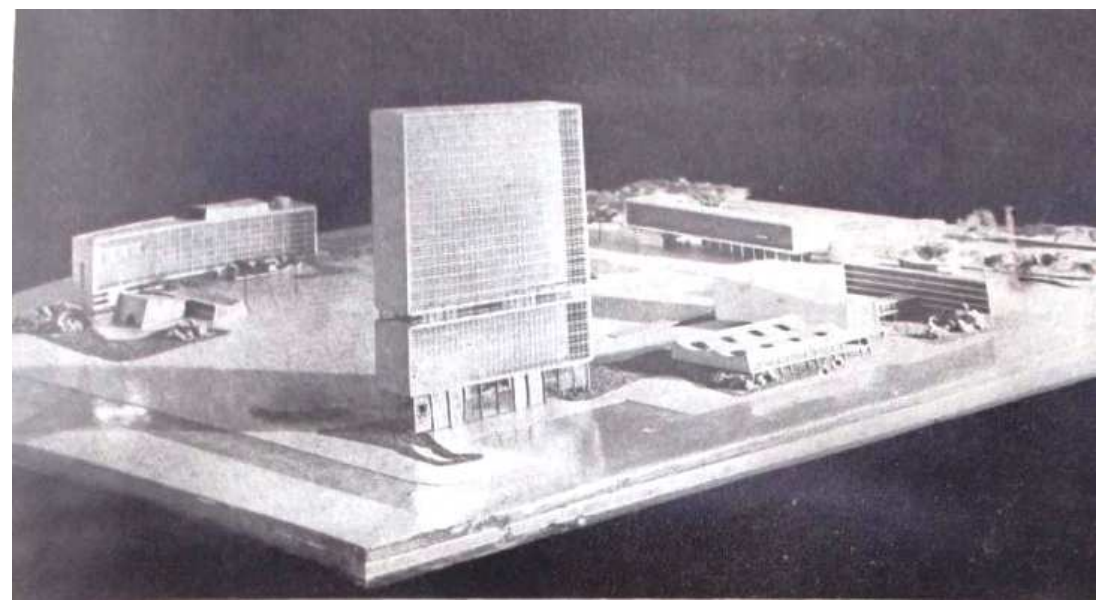

Figura 07: Maquete do Centro Cívico. In $1^{\circ}$ Centenário da Emancipação Política do Paraná:1853 - 1953. [S.1.]: Câmara de Expansão Econômica do Paraná, [1953]. p. 67.

Em um período histórico em que a ocupação do território era sinônimo de progresso e civilização, a derrubada das matas para a construção ou modernização de cidades era vista como o ápice do desenvolvimento. Muitas das cidades do Norte e Oeste do Paraná foram criadas na década de 1950, e as imagens das cidades que se erguiam "onde antes só havia mata" foram exploradas nos impressos analisados neste estudo. 
Cadernos de Clio, Curitiba, v. 6, nº 2, 2015

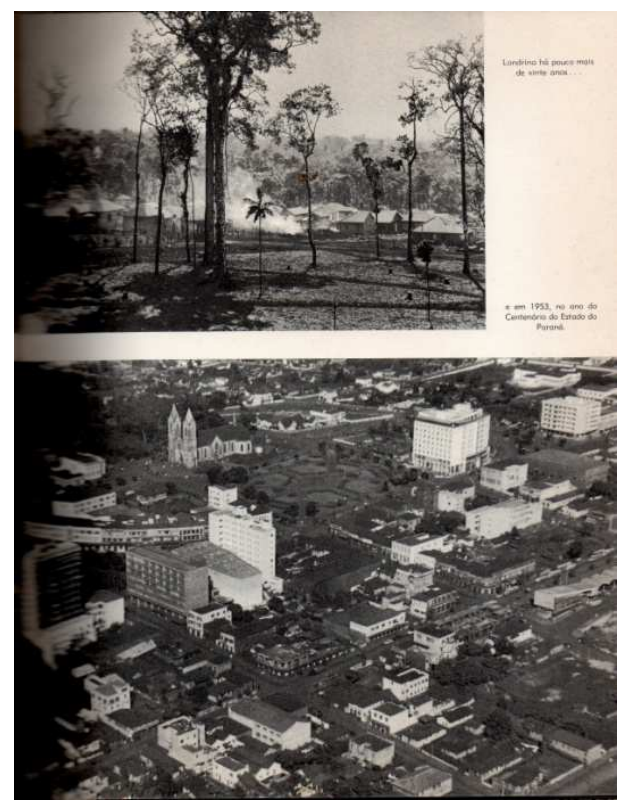

Figura 08: Acima, Londrina na década de 1930, ainda coberta pela mata e, abaixo, no ano do Centenário, com muitos prédios. In Álbum do Centenário [1953]

Em um estudo sobre as transformações do espaço urbano de Curitiba, o Historiador Antônio Cesar de Almeida Santos (1999) constatou, com base no depoimento de testemunhas oculares dos eventos analisados, que as comemorações ao Centenário do Paraná marcam uma baliza entre o Paraná de ontem, tradicional, antigo, representado pela Praça Tiradentes e seu entorno, com o Paraná do futuro, moderno, vinculado ao conjunto arquitetônico do Centro Cívico e as demais obras construídas por ocasião do Centenário. Os entrevistados de Santos relacionam a Curitiba de "hoje" (as entrevistas foram realizadas na primeira metade 
da década de 1990) com as modernizações ocorridas durante o Governo Munhoz da Rocha, governador do Estado entre 1951 e 1955.

O impresso intitulado Álbum do Centenário do Paraná, publicado pelo governo em 1953, possui fotografias com breves legendas e mensagens de enaltecimento ao Estado. Algumas fotografias têm como objetivo comparar o "Paraná de ontem" e o "Paraná do futuro". As imagens mostram o contraste entre as pequenas casas de madeira e os "altos edifícios" que se erguiam (FIGURA 09 e 10).

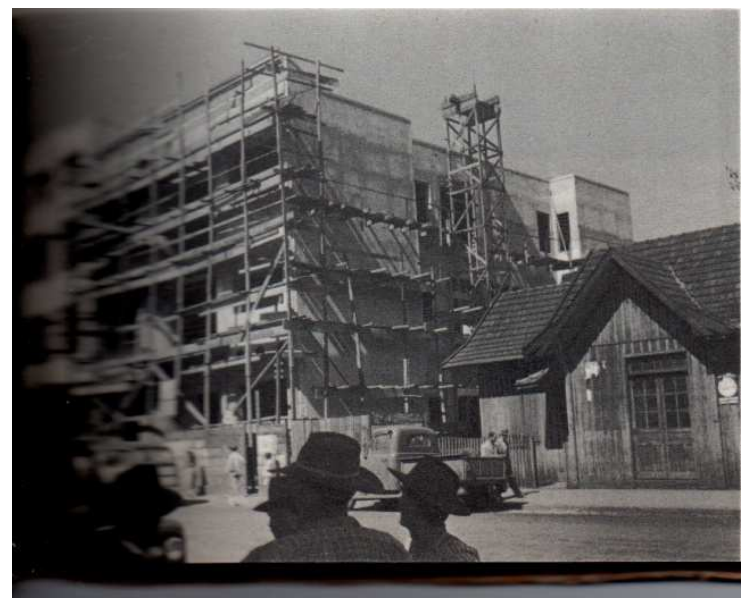

Figura 09: Ao lado da casa de madeira levanta-se um edifício. In Álbum do Centenário [1953]

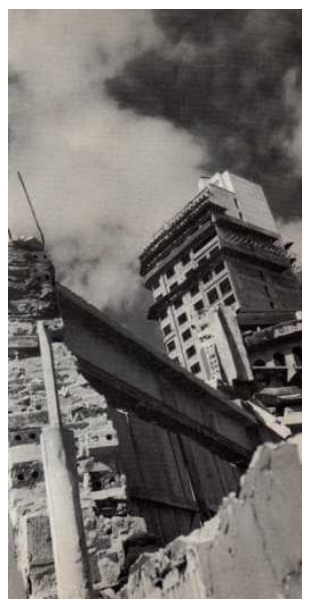

Figura 10: O velho cai e o novo sobe. In Álbum do Centenário [1953]

As fotografias atendem a técnicas de estetização do espaço social, com belos ângulos e composições voltadas a representar o belo e a monumentalidade. As composições apresentam os monumentos acompanhados de assuntos de proporções menores, como pessoas, pequenas casas e automóveis, causando um contraste que valoriza o monumental. 


\section{Considerações finais}

Nas duas publicações analisadas, nota-se que a paisagem se impõe como recurso usado para forjar uma especificidade para o Paraná. Parece-nos razoável afirmar que as teorias novecentistas relacionadas ao meio e raça, que tanto influenciaram os intelectuais paranistas no limiar do século XX, chegaram incólumes aos anos 1950, e contribuíram para que a paisagem permanecesse como a especificidade do Paraná.

Entendemos que as construções identitárias não são unânimes, haja vista que as frações de poder travam essas lutas em um campo de força que reúne pontos de vista antagônicos. O próprio movimento paranista teve seus adversários, sendo o principal deles o escritor Dalton Trevisan que, por meio da revista Joaquim, publicou diversos artigos que combatiam os ideais desse movimento (Oliveira, 2009)

Assim, percebemos que a especificidade paranaense nas publicações analisadas não está representada através de um tipo característico do Paraná, isto é, no discurso identitário não há um homem paranaense típico. A paisagem, como vimos, foi a alternativa encontrada pelas elites para fortalecer a comunidade imaginada paranaense.

Os monumentos erigidos para o Centenário, bem como suas imagens captadas pela fotografia e publicadas por meio de revistas oficias, caracterizam elementos de uma comunidade imaginada integrados em uma estrutura que visava conectar os paranaenses. A evocação de um espaço social harmônico e belo compartilhado por todos os paranaenses atuava, enquanto paisagem simbólica, como um fenômeno capaz de 
ativar o processo de rememoração, tão importante durante a cerimônia de massa praticada nas comemorações ao Centenário.

Concluímos, assim, que as fotografias foram importantes instrumentos utilizados pelas elites dirigentes na época do Centenário, na tentativa de construir uma identidade para o Paraná, uma vez que a imagem técnica foi instrumentalizada para apresentar, através de ângulos elegantes, a monumentalidade de construções arquitetônicas, sugerindo a ideia de progresso e de Paraná moderno; agregando novas imagens no âmbito da comunidade imaginada paranaense.

\section{Referências Bibliográficas}

ANDERSON, Benedict R. O'G. (Benedict Richard O'Gorman). Comunidades imaginadas: reflexões sobre a origem e a difusão do nacionalismo. São Paulo: Companhia das Letras, 2008.

BAHLS, Aparecida Vaz da Silva; RODRIGUES, Helenice. A busca de valores identitários: a memória histórica paranaense. 2007. 192 p. Tese (Doutorado) - Universidade Federal do Paraná. Setor de Ciências Humanas, Letras e Artes. Curso de Pós Graduação em História.

BORGES, Eliana; FRESSATO, Soleni. A arte em seu estado: história da arte paranaense. Curitiba, PR: Medusa, 2008. 1 v.

BOSI, Ecléa. Memória e Sociedade: Lembrança de velhos. 2.ed.São Paulo, 1987.

CAMARGO, Geraldo Leao Veiga de. Paranismo: arte, ideologia e relações sociais no Paraná: 1853 - 1953. 2007. 213f. Tese (doutorado) Universidade Federal do Paraná, Setor de Ciencias Humanas, Letras e Artes, Programa de Pós-Graduaçao em História. Defesa: Curitiba, 2007. 
HOBSBAWM, Eric J. Nações e nacionalismos desde 1870. Rio de Janeiro: Paz e Terra. 2002.

MAUAD, Ana Maria; Marcos Felipe de Brum Lopes. História e Fotografia. In CARDOSO, Ciro Flamarion; VAINFAS, Ronaldo. Novos Domínios da História. Rio de Janeiro: Elsevier, 2012.

MENESES, Ulpiano T. Bezerra de. História e imagem: iconografia/iconologia e além. In CARDOSO, Ciro Flamarion; VAINFAS, Ronaldo. Novos Domínios da História. Rio de Janeiro: Elsevier, 2012.

MOTTA, Márcia Maria Menendes. História, memória e tempo presente. In CARDOSO, Ciro Flamarion; VAINFAS, Ronaldo. Novos Domínios da História. Rio de Janeiro: Elsevier, 2012.

MOTTA, Neli Gehlen. 'A miséria que acompanha o progresso': discursos e contradições no Centenário Paranaense (1953). 2014. (Apresentação de Trabalho/Outra).

NORA, Pierre. Entre história e memória: a problemática dos lugares. Projeto História. São Paulo. 1993.

OLIVEIRA, Lúcia Lippi. As festas que a República manda guardar. Estudos Históricos. 1989.

OLIVEIRA, Luiz Claudio Soares de. Dalton Trevisan (en)contra o paranismo. Curitiba: Travessa dos Editores, 2009.

PALUDO, G. B.; BARROS, D. A. Síntese da História do Paraná. Cascavel: Assoeste (Associação Educacional do Oeste do Paraná), 1995.

REBELO, Vanderlei. Bento Munhoz da Rocha: o intelectual na correnteza política. Curitiba: Sesquicentenário, 2005.

RICOEUR, Paul. A memória, a história, o esquecimento. Campinas, SP: Ed. da UNICAMP, 2007. 
ROCHA NETO, Bento Munhoz da. O Paraná, ensaios. Curitiba, PR: Fundação Cultural, 1995.

SANTOS, Antonio César de Almeida. Memórias e cidade: depoimentos e transformação urbana de Curitiba 1930-1990. 2. ed. Curitiba: Aos Quatro Ventos, 1999.

SILVA, Helenice Rodrigues. "Rememoração"/comemoração: as utilizações sociais da memória. Revista Brasileira de História, vol.22, n44, São Paulo, 2002.

WACHOWICZ, Ruy Christovam. História do Paraná. 10.ed. Ponta Grossa (PR): Ed. UEPG, 2010.

\section{Fontes}

$1{ }^{\circ}$ Centenário da Emancipação Política do Paraná: 1853 - 1953. [S.1.]: Câmara de Expansão Econômica do Paraná, [1953].

Paraná, Brasil. Album do Centenário, 1953.

Recebido em: 14/06/2015 Aceito em: 22/11/2015 